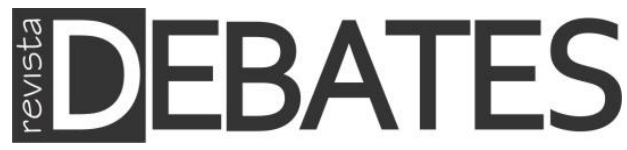

\title{
Punição eleitoral e contas irregulares nas eleições para prefeito (2004-2016)
}

\author{
Electoral punishment and creative accounting in mayors' elections \\ (2004 - 2016)
}

\section{Augusta Teixeira \\ Marjorie Marona}

\section{Resumo}

Candidatos a prefeito com problemas em suas contas são punidos eleitoralmente? Buscamos responder se o eleitor consegue controlar seu representante. Analisamos os candidatos a prefeitos entre os anos 2004 a 2016. Buscamos agentes que tiveram suas contas julgadas como irregulares pelo Tribunal de Contas da União, tendo sido detentores de cargos públicos ou não. Utilizamos como variáveis de controle o gasto dos candidatos, se o candidato é incumbente ou não; migração partidária; tamanho populacional dos municípios e renda per capita. Com um modelo de regressão logística com link logit, estimamos o efeito de uma ou mais variáveis independentes em uma variável dependente binária. Nossos resultados indicam que apenas 35\% dos envolvidos com contas irregulares foram eleitos. Percebemos que entre desafiante e incumbente com contas irregulares, o incumbente tem mais chances de reeleição do que o desafiante tem de vencer.

\section{Palavras-chave}

Accountability, Eleições; Corrupção.

\section{Abstract}

The main purpose of this work is to measure the effect of "creative accounting" in mayoral election. We want to measure the effect of creative accounting judged by Tribunal de Contas da União (TCU) in elections. Our unit of analysis are the mayoral elections between 2004-2016. We look for agents with creative accounting judged by TCU, whether they hold public office or not. As control variables we used campaign finance, whether the candidate was incumbent or not, party switching, population size and income per capita. Using a logistic regression, we try to estimate the effect of one or more independent variables in a dependent binary variable. Our results indicated that $35 \%$ of candidates responsible for creative accounting were elected. The model also indicates that between challenger and incumbent with creative accounting, incumbents have more chances to be reelected than challengers have to win.

\section{Keywords}

Accountability; Elections; Corruption. 
114 | Augusta Teixeira e Marjorie Marona

\section{Introdução ${ }^{1}$}

Qual o efeito de contas julgadas como irregulares na eleição de prefeitos? Nosso objetivo é mensurar o efeito do julgamento de contas irregulares pelo Tribunal de Contas da União (TCU) nas eleições para prefeitos e na capacidade do eleitor em punir tais agentes.

Os dispositivos de accountability têm como uma de suas funçôes barrar a vitória de candidatos com histórico de conduta ilegal (MANIN, PRZEWORSKI e STOKES, 1999). Neste trabalho observamos o efeito que a accountability horizontal tem na accountability vertical.

Os estudos de Pereira e Melo (2015) e Winters e Weitz-Shapiro (2013) buscam analisar a relação entre os delitos cometidos e o sucesso obtido nas reeleiçôes. O resultado é que uma grande parcela de eleitores que não consegue distinguir os candidatos com histórico de corrupção dos probos, devido, principalmente, à falta de informação. Tal resultado corrobora com a teoria que aponta a incapacidade do eleitorado em punir candidatos (MANIN, PRZEWORSKI e STOKES, 1999; O'DONNELL, 1998). Portanto, observamos que há sucesso eleitoral dos candidatos com comportamentos desviantes, o que indiretamente favorece a corrupção (PEREIRA e MELO, 2015).

Propomos dividir este artigo em três seções: primeiramente, exploramos o que a literatura nos oferece sobre accountability; em seguida apresentamos os testes das variáveis que serão levadas em conta para assegurar o melhor resultado; por último, apresentamos aos resultados obtidos em conjunto com a teoria. Acreditamos que a irregularidade apontada pelo TCU reduz a possibilidade de eleiçôes de desafiantes, enquanto os incumbentes têm mais possibilidades de reeleição por estarem com a máquina pública.

Utilizamos uma regressão logística para analisar os dados disponibilizados pelos TCU e TSE (Tribunal Superior Eleitoral) sobre julgamentos de contas das prefeituras e eleições.

\footnotetext{
1 Este artigo surgiu da dissertação da primeira autora, defendida na Universidade Federal de Pernambuco, sob orientação do prof. Dr. Marcus André Melo - a quem agradecemos todas as contribuiçóes, assim como as da banca. De 2017 para cá, decidimos modificar um pouco a parte teórica e chegamos a este resultado. Agradecemos as sugestões dos avaliadores da revista Debates.
} 


\section{Uma breve revisão teórica sobre accountability}

Segundo com Arantes e Couto (2010, p. 570), “[...] democracias constitucionais caracterizam-se pela existência de mecanismos de limitação ao exercício do poder político", ou seja, um sistema de freios e contrapesos, tais como poder de veto, accountability e divisão de poderes. A questão fundamental da accountability refere-se à capacidade de responsividade e responsabilidade dos agentes públicos, logo, que todas as atividades públicas devam ser envolvidas numa pauta de prestação de contas (MAINWARING, 2003).

Como o conceito de accountability não é exclusivo da Ciência Política, Mainwaring (2003) introduz o conceito de accountability política. Ela é apresentada como uma relação formal de supervisão e/ou sançôes de agentes públicos por outros atores. Não implica apenas na questão da responsividade dos sujeitos, mas também na obrigação legal com a prestação de contas. A accountability política pode ser realizada por dois tipos de atores: (1) os eleitos pelo voto da população; (2) e os comitês legislativos.

A chamada accountability democrática considera atores eleitos e não-eleitos. Os atores não-eleitos são indicados pelos eleitos e também devem ser accountables, seja ao Executivo ou ao Legislativo, o que não significa prescindir da sua autonomia para realizar seu trabalho. (MAINWARING, 2003).

Este último ponto conduz uma questão amplamente discutida na accountability: a relação entre mandante-agente. Segundo Fearon (1999) as relaçóes envolvendo accountability são chamadas de agency relationships - são elas que garantem que o agente seja o mais accountable possível ao seu mandante. Para garantir uma relação eficaz de accountability, é necessário que os agentes: (i) apresentem informaçóes sobre suas açôes ao mandante; (ii) justifiquem suas açóes; (iii) possam sofrer sanções ou ser premiados pelos mandantes (TOMIO e ROBL FILHO, 2013).

Existem mais outros dois tipos de accountability que são estudados pela Ciência Política: a accountability vertical e a accountability horizontal. Segundo Manin, Przeworski e Stokes (1999) e O’Donnell (1998), a accountability vertical está intrinsecamente ligada às eleiçóes livres e justas, seguindo os pressupostos apresentados por Dahl (2001 e 2012). Através das eleições, cidadãos exercem pelo voto a punição ou premiação de representantes (O'DONNELL, 1998; MANIN, PRZEWORSKI e STOKES, 1999), sancionando ou não agentes públicos eletivos (PEREIRA, RENNÓ e SAMUELS, 2011) - ainda que sejam considerados os 
diferentes tipos de desenhos institucionais eleitorais e a capacidade desses eleitores adquirirem mais ou menos informaçáo acerca do sistema e do comportamento público dos representantes. O’Donnell (1998) e Manin, Przeworski e Stokes (1999) apontam que, mesmo que as eleiçóes sejam consideradas um dos poucos mecanismos de escolhas de políticas e de sanção de indivíduos com performances insuficientes, elas apresentam problemas, como a lacuna de tempo de uma eleição para a outra, reduzindo a eficácia da accountability vertical ${ }^{2}$. Já Pereira, Rennó e Samuels (2011) apontam outras limitações para o cenário da accountability vertical, como: problemas relacionados à patronagem e cargos ocupados sem suporte eleitoral.

O’Donnell (1998) assinala que a accountability vertical assegura que os países que a exercem são considerados democráticos, porém há necessidade de agências de controle. O’Donnell (1998) defende a existência de agências que tenham autonomia e estejam dispostas a supervisionar, controlar e punir outras agências, fortalecendo a transparência institucional e garantindo ao cidadão a certeza da responsabilidade dos representantes. Tais agências constituem mecanismos de accountability horizontal. Porém, esses mecanismos frequentemente falham ao impedir que contraventores se candidatem para cargos eleitorais (BOAS, HILDAGO e MELO, 2017).

O problema do controle no Brasil dá-se de uma forma paradoxal com a teoria da accountability: segundo Filgueiras e Marona (2012), os escândalos de corrupção são constantes e impóem inovaçóes institucionais, porém, a percepção da corrupção não diminui. Precisamos pontuar que, apesar do avanço no controle burocráticoadministrativo, da melhoria na transparência e incentivo para que os órgãos de controle atuem de uma forma mais incisiva, tais fatores não implicam numa redução na corrupção ou na percepção (FILGUEIRAS e MARONA, 2012).

Portanto, a partir desta discussão sobre esses dois tipos de accountability, apontamos onde este artigo se insere: nosso objetivo é mensurar o efeito do julgamento das contas irregulares pelo TCU nas eleiçóes para prefeitos e na capacidade do eleitor em punir tais agentes. Ou seja, o TCU enquanto agência cumpre o papel de accountability horizontal e o eleitor é um dos responsáveis pela accountability vertical. Assim, tentamos observar se, neste caso, a accountability funciona ou não.

\footnotetext{
${ }^{2}$ A questão do voto apontada por Manin, Przeworski e Stokes. (1999) é vista como voto retrospectivo e voto prospectivo. $\mathrm{O}$ voto retrospectivo também é apontado como um problema para a accountability vertical, pois o eleitor precisaria esperar um mandato para avaliar a performance do seu representante e só nas eleições seguintes sancionar.
} 


\section{Metodologia}

Aqui apresentamos o desenho de pesquisa adotado, as fontes dos dados, as variáveis selecionadas e o procedimento metodológico adotado para testar as hipóteses deste trabalho.

Nosso ponto de partida é a base de dados de contas julgadas irregulares do TCU, que apresenta todos os agentes, tanto do setor público quanto privado, que tiveram suas contas julgadas como irregulares (prefeituras, secretarias ou fornecimento de serviços). Os casos presentes nessa lista podem ou não ter sido detentores de cargo ou função pública. Esses dados são enviados aos Tribunais Regionais Eleitorais (TRE) próximo ao período de registro de candidaturas ${ }^{3}$. Isso não significa que os nomes constantes nesta lista foram condenados ou considerados inelegíveis, pois tal decisão cabe à Justiça Eleitoral. Inúmeros casos acabam sendo penalizados com multas referentes à rejeição de suas contas, contudo seus nomes não são retirados dessa lista.

Para fins de análise eleitoral, compatibilizamos as informações dos nomes constantes na lista do TCU com os dados eleitorais do TSE. Os dados de identificação disponibilizados são: nome, a sigla do Estado (UF) e o número do CPF dos indivíduos. $\mathrm{O}$ procedimento adotado foi totalmente automatizado: realizamos uma combinação entre essas variáveis e aquelas dos dados eleitorais. A redução no número de casos é alta já que existem possíveis problemas com essa abordagem. Dentre eles, listamos: (1) os nomes dos indivíduos podem estar escritos de maneiras diferentes, falta de sobrenomes ou digitação errada; (2) o número do CPF pode ter sido digitado incorretamente. Essas duas variáveis, mais a UF dos indivíduos, são as únicas formas de juntarmos a base de dados do TCU com a do TSE de forma automática.

Salientamos que esse procedimento não enviesa os resultados, já que não foram identificados problemas de erro sistemático na construção da base de dados. Assim, os casos utilizados apresentam verdadeiramente a característica de interesse: possuir contas declaradas irregulares pelo TCU. Além disso, o TCU avalia as contas desses agentes com base em uma amostra aleatória, aspecto fundamental para a utilização dos modelos estatísticos.

Já os dados do TSE, quanto mais regredidos no tempo, menos confiáveis são, já que as bases de dados apresentam diversas inconsistências. Ainda, os dados de

\footnotetext{
${ }^{3}$ A lista está disponível no site do TCU. Disponível em: <http://portal.tcu.gov.br/responsabilizacaopublica/contas-julgadas-irregulares/>. Acesso em: 06 maio 2019.
} 
receitas de campanha são incomparáveis em termos de unidade da federação para as eleiçóes de 2000 e anteriores a ela. Outra variável importante nos estudos eleitorais se refere a se o candidato é mandante ou desafiante e só pode ser calculada com uma eleição anterior à de interesse. Nesse caso, para que seja possível saber se um candidato é mandante em $t$ precisamos dos dados eleitorais em $t$-1. Por questão de disponibilidade de dados, serão observadas as eleições a partir de 2004.

Para os dados do TSE foram excluídas todas as eleiçóes suplementares e o desempenho eleitoral dos candidatos em segundo turno. As disputas em segundo turno e as disputas suplementares possuem caráter atípico e apresentam problemas para a sistematização dos dados em larga escala. Excluímos também casos em que o resultado eleitoral ou receita de campanha não estavam disponíveis, seja por inexistência dos dados nos repositórios ou por problemas de reportação do TSE.

Todos os casos na base do TCU com processos que datavam de antes de 2000 foram retirados da base. Dada a dificuldade em vincular o período do processo com o período eleitoral, não é possível trabalhar com os dados na forma que eles são reportados pelo TCU, já que a unidade de análise é o processo dos agentes. Assim, cada agente será repetido conforme a quantidade de processos que forem movidos contra ele. Optamos por agrupar os dados por nome do sujeito e número de processos no período eleitoral. Os processos que datam do ano seguinte à eleição $x$ até o ano da próxima eleição y são categorizados como pertencendo ao ciclo eleitoral de $y$; por exemplo, o candidato $i$ teria disputado a eleição y já com suas contas rejeitadas. Isso significa que os processos que datam de 2001 até 2004 pertencem ao ciclo eleitoral 2004. Logo, para um candidato que teve sua conta julgada irregular entre 2001 e 2004 e, supostamente, teve sua imagem afetada por isto, acreditamos que seu desempenho eleitoral também será afetado.

Entendemos que seria importante medir o efeito das contas rejeitadas na votação de um prefeito entre sua eleição em $t$ em sua tentativa de reeleição em $t+1$. Porém, foi possível observar por meio dos dados que diversos candidatos tiveram suas contas rejeitadas quando ainda não eram prefeitos, ou eram prefeitos e não concorreram à reeleição (às vezes sendo substituídos), ou, ainda, vários deles tiveram suas contas consideradas irregulares em seu segundo mandato. Como poderá ser visto adiante, após todos os procedimentos de limpeza, compatibilização e sistematização dos dados, nosso número da amostra $(N)$ se restringe a 516 casos que pleitearam eleiçóes com contas rejeitadas. Muitos tiveram suas contas rejeitadas após a reeleição e isso impediu que seu desempenho eleitoral fosse avaliado. 
Foi preciso estabelecer parâmetros mínimos de comparação entre unidades tão distintas como são os municípios brasileiros, que podem apresentar variação significativa em densidade populacional e nível de renda. Para contornar isso, coletamos variáveis regularmente usadas nesse tipo de estudo no site do IBGE.

O processo de limpeza e manipulação de dados foi efetuado com o auxílio do Microsoft Excel 2013 e o R (R CORE TEAM, 2016) em sua versão 3.3.1, sendo este a fonte dos nossos dados eleitorais, através do pacote o electionsBR (MEIRELES, SILVA e COSTA, 2016). O Quadro 1 contém todas as variáveis que mobilizamos:

\section{Quadro 1 - Variáveis}

\begin{tabular}{|c|c|c|}
\hline Variável & Descrição & Tipo \\
\hline Ano da Eleição & $\begin{array}{l}\text { Apresenta o ano que em a eleição ocorreu }(2004,2008,2012 \text {, } \\
\text { 2016). }\end{array}$ & Data, ANO \\
\hline Estado & $\begin{array}{l}\text { O estado a que o município onde ocorre a eleição está } \\
\text { vinculado. Contamos com informaçóes para os } 26 \text { estados, } \\
\text { mais o Distrito Federal. }\end{array}$ & Texto \\
\hline Município & $\begin{array}{l}\text { Nome do município onde ocorre a eleição. Possuímos } \\
\text { informação para } 5.271 \text { municípios em 2004; } 5.274 \text { em 2008; } \\
5.287 \text { em } 2012 \text { e } 2016 \text {. }\end{array}$ & Texto \\
\hline Partido Político & $\begin{array}{l}\text { Sigla e número dos partidos que apresentaram candidatos nos } \\
\text { pleitos para os cargos de prefeito. }\end{array}$ & Texto \\
\hline Candidato & Nome do Candidato. & Texto \\
\hline Votos & Total de votos do candidato em primeiro turno. & Numérico \\
\hline Percentual de Votos & Percentual de votos do candidato em primeiro turno. & Numérico \\
\hline Resultado Eleitoral & $\begin{array}{l}\text { Situação eleitoral do candidato ao fim da eleição: Eleito e Não } \\
\text { Eleitos. }\end{array}$ & Categórica \\
\hline Sexo & Descreve o sexo do candidato: Masculino ou Feminino. & Categórica \\
\hline Gasto de Campanha & Total de dinheiro gasto na campanha. & Numérico \\
\hline Migração Partidária & $\begin{array}{l}\text { Descreve se o candidato migrou de partido em relação à eleição } \\
\text { precedente. }\end{array}$ & Categórica \\
\hline Incumbente & Descreve se o candidato é mandatário ou desafiante. & Categórica \\
\hline $\begin{array}{l}\text { Conta Irregular na } \\
\text { Amostra }\end{array}$ & $\begin{array}{l}\text { Identifica se o candidato possui alguma conta declarada } \\
\text { irregular no período em estudo. }\end{array}$ & Categórica \\
\hline $\begin{array}{l}\text { Irregularidade nas } \\
\text { Contas }\end{array}$ & $\begin{array}{l}\text { Descreve se o candidato possui conta com irregularidade no } \\
\text { ciclo eleitoral em que ele disputou. }\end{array}$ & Categórica \\
\hline $\begin{array}{l}\text { Número de } \\
\text { Processos }\end{array}$ & $\begin{array}{l}\text { Número de processos do TCU que o candidato respondeu no } \\
\text { ciclo eleitoral em que ele disputou a eleição. }\end{array}$ & Numérico \\
\hline
\end{tabular}




\begin{tabular}{|l|l|l|}
\hline $\begin{array}{l}\text { Tempo de } \\
\text { Julgamento }\end{array}$ & $\begin{array}{l}\text { Média do tempo de julgamento dos processos que o candidato } \\
\text { respondeu. }\end{array}$ & Numérico \\
\hline PIB per capta & PIB per capta dos municípios no ano da eleição. & Numérico \\
\hline
\end{tabular}

Fonte: Elaborado pelas autoras.

O conjunto de variáveis foi construído baseado nos estudos eleitorais, a saber: (a) variáveis do candidato; (b) variáveis do envolvimento em contas irregulares, e (c) variáveis relacionadas aos municípios onde a competição partidária eleitoral acontece.

A variável dependente é o resultado eleitoral dos candidatos, mensurada como eleito ou não. No nível do candidato coletamos as informaçóes de gastos de campanha, se é incumbente ou mandatário e se migrou de partidos em relação à eleição anterior, com objetivo de controlar as relaçóes no teste de hipótese. De acordo com a literatura, gastos de campanha exercem um efeito positivo e significativo sobre o desempenho eleitoral dos candidatos (JACOBSON, 1985), de modo que é importante controlar seu efeito sobre nossa variável dependente. Ademais, identificamos se o candidato é incumbente ou desafiante, nos permitindo controlar também os possíveis efeitos de ser mandatário. Diversos estudos indicam que o candidato mandatário possui vários tipos de vantagens ao buscar reeleição, principalmente o uso da máquina política (GELMAN e KING, 1990; BORGES, 2010). Por fim, a migração partidária pode estar relacionada com o desempenho do candidato na eleição seguinte, já que, ainda que se discuta se são benéficos os efeitos da migração partidária, mudar de partido faz parte de uma estratégia de sobrevivência e ambição política (MELO, 2002).

A variável independente é binária e indica se o candidato teve contas declaradas irregulares pelo TCU no ciclo eleitoral em que ele disputou. Destarte, ela flagra se o sujeito se candidatou tendo contas rejeitadas, podendo medir o efeito disso sobre seu desempenho eleitoral subsequente. Mais além, contabilizamos o número de processos do TCU por ciclo eleitoral e a média do tempo de julgamento desses processos.

Por fim, trouxemos variáveis de controle da nossa unidade geográfica. Em primeiro lugar, o tamanho populacional do município, seguido da coleta de dados de renda per capita para controlar especificidades baseada no nível de riqueza. Utilizamos essas variáveis devido ao trabalho de Deninger e Squire (1996), que aponta que a corrupção afeta o coeficiente Gini e produz desigualdade. Nosso objetivo é impedir que a relação entre pobreza e corrupção interfira nos testes de hipóteses. 
Testaremos, como indicado no desenho de pesquisa, a seguinte hipótese: candidatos com contas irregulares possuem uma menor probabilidade de serem eleitos quando comparados com aqueles que não respondem a esses processos.

Utilizaremos um modelo de regressão logística com link logit. Esse modelo é usado quando se quer estimar o efeito de uma ou mais variáveis independentes em uma determinada variável dependente binária.

\section{Análise dos dados}

Tendo como objetivo acessar a punição eleitoral, analisaremos o desempenho de candidatos que disputam as eleições com seus nomes vinculados a contas rejeitadas pelo TCU.

Inicialmente, analisaremos esses dados para todos os candidatos que tiveram suas contas rejeitadas, independentemente do mandato eleitoral. Posteriormente, avaliaremos aqueles casos que possuem contas rejeitadas e buscam a reeleição na disputa seguinte ${ }^{4}$. Iniciaremos apresentando dados acerca do número de casos e do nosso objeto.

Tabela 1 - Nomes envolvidos com contas irregulares (2004-2016)

\begin{tabular}{c|l|l|l|l|l}
\hline \multicolumn{2}{c|}{} & Frequência & Porcentagem & $\begin{array}{l}\text { Porcentagem } \\
\text { válida }\end{array}$ & $\begin{array}{l}\text { Porcentagem } \\
\text { cumulativa }\end{array}$ \\
\hline \multirow{3}{*}{ Válido } & Não & 59323 & 96,00 & 96,00 & 96,00 \\
\cline { 2 - 6 } & Sim & 2466 & 4,00 & 4,00 & 100,00 \\
\cline { 2 - 6 } & Total & 61789 & 100,0 & 100,0 & \\
\hline
\end{tabular}

Fonte: Elaborado pelas autoras com os dados do TCU e do TSE.

A tabela acima indica quantos candidatos, de todos que disputaram a partir de 2004, tiveram alguma conta rejeitada. Precisamos ter cautela para interpretar esses números, já que diversos dos casos só tiveram as contas rejeitadas após seu mandato terminar. Outros disputaram as eleições em 2004, porém seus nomes só foram envolvidos nesses processos em 2016. Com isso em mente, a tabela indica que $4 \%$ dos candidatos que disputaram entre 2004 e 2016 tiveram suas contas declaradas irregulares pelo TCU. Esse número é bem menor quando analisamos apenas aqueles

\footnotetext{
${ }^{4}$ Dado o número de casos, as análises estatísticas para esse grupo de casos não podem ser de técnicas robustas; assim, avaliamos apenas as comparações de médias. Seria necessário avaliaçóes small-n a esse respeito para buscar inferências causais generalizantes.
} 
que disputaram as eleições tendo contas irregulares no termo do mandato anterior. A tabela abaixo resume essas informaçóes:

Tabela 2 - Candidatos com contas irregulares disputando eleição (2004-2016)

\begin{tabular}{c|c|c|c|c|c}
\hline \multicolumn{2}{c|}{} & Frequência & Porcentagem & $\begin{array}{c}\text { Porcentagem } \\
\text { válida }\end{array}$ & $\begin{array}{c}\text { Porcentagem } \\
\text { cumulativa }\end{array}$ \\
\hline \multirow{3}{*}{ Válido } & Não & 61273 & 99,16 & 99,16 & 99,16 \\
\cline { 2 - 6 } & Sim & 516 &, 84 &, 84 & 100,00 \\
\cline { 2 - 6 } & Total & 61789 & 100,00 & 100,00 & \\
\hline
\end{tabular}

Fonte: Elaborado pelas autoras com os dados do TCU e do TSE.

Nossa base possui 516 candidatos que disputaram as eleições com contas irregulares, representando $0,84 \%$ da nossa amostra. Isso significa que esses candidatos foram processados e lançaram candidatura na eleição seguinte: esses são os casos em que estamos interessados, portanto precisamos avaliar o desempenho desses candidatos comparando com os demais. Existe uma variação no número de processos de cada candidato que forma o grupo dos que concorreram com contas irregulares, além disso, existe variação também no tempo de julgamento desses processos.

Por ciclo eleitoral, a média do número de processos dos candidatos com contas irregulares é de 1,37 , com desvio padrão de 0,896 . Esse desvio padrão indica a existência de variação razoável na amostra. Na nossa amostra, 705 processos de contas irregulares foram movidos contra esses candidatos.

Nosso número de casos totaliza em 516, sendo que 82 deles disputaram as eleições em 2004, e 277 em 2008. Em 2012, houve uma queda nesse número (117) e 2016 foi a eleição com menor presença desse tipo de candidato, com apenas 40 casos.

A Tabela 3 apresenta a distribuição de candidatos com contas irregulares por partido político. 
Tabela 3 - Descritivos número de candidatos com contas irregulares por partido

\begin{tabular}{|c|c|c|c|c|}
\hline & Frequência & Porcentagem & $\begin{array}{c}\text { Porcentagem } \\
\text { válida } \\
\end{array}$ & $\begin{array}{l}\text { Porcentagem } \\
\text { cumulativa }\end{array}$ \\
\hline DEM & 38 & 7,36 & 7,36 & 7,36 \\
\hline PC do B & 3 &, 58 &, 58 & 7,95 \\
\hline PDT & 36 & 6,98 & 6,98 & 14,92 \\
\hline PEN & 1 &, 19 &, 19 & 15,12 \\
\hline PFL & 16 & 3,10 & 3,10 & 18,22 \\
\hline PHS & 3 &, 58 &, 58 & 18,80 \\
\hline $\mathrm{PL}$ & 6 & 1,16 & 1,16 & 19,96 \\
\hline PMDB & 109 & 21,12 & 21,12 & 41,09 \\
\hline PMN & 6 & 1,16 & 1,16 & 42,25 \\
\hline $\mathrm{PP}$ & 28 & 5,43 & 5,43 & 47,67 \\
\hline PPS & 16 & 3,10 & 3,10 & 50,78 \\
\hline PR & 45 & 8,72 & 8,72 & 59,50 \\
\hline PRB & 5 & ,97 & 97 & 60,47 \\
\hline PROS & 1 &, 19 &, 19 & 60,66 \\
\hline PRP & 6 & 1,16 & 1,16 & 61,82 \\
\hline PRTB & 2 &, 39 &, 39 & 62,21 \\
\hline PSB & 31 & 6,01 & 6,01 & 68,22 \\
\hline PSC & 5 & ,97 & ,97 & 69,19 \\
\hline PSD & 19 & 3,68 & 3,68 & 72,87 \\
\hline PSDB & 68 & 13,18 & 13,18 & 86,05 \\
\hline PSDC & 2 &, 39 & ,39 & 86,43 \\
\hline PSL & 3 &, 58 &, 58 & 87,02 \\
\hline PT & 23 & 4,46 & 4,46 & 91,47 \\
\hline PT do B & 1 &, 19 &, 19 & 91,67 \\
\hline PTB & 24 & 4,65 & 4,65 & 96,32 \\
\hline PTC & 3 &, 58 &, 58 & 96,90 \\
\hline PTN & 4 &, 78 & ,78 & 97,67 \\
\hline PV & 12 & 2,33 & 2,33 & 100,00 \\
\hline Total & 516 & 100,00 & 100,00 & \\
\hline
\end{tabular}

Fonte: Elaborado pelas autoras com os dados do TCU e do TSE.

De maneira geral, praticamente todos os partidos apresentaram algum candidato com esse tipo de problema. A Tabela 4 apresenta as informaçóes sobre a migração partidária dos candidatos com contas irregulares por ano eleitoral: 
124 | Augusta Teixeira e Marjorie Marona

Tabela 4 - Migração partidária dos candidatos conta irregular por eleição

\begin{tabular}{|c|c|c|c|c|c|c|}
\hline & & & Frequência & Porcentagem & $\begin{array}{c}\text { Porcentagem } \\
\text { válida }\end{array}$ & $\begin{array}{l}\text { Porcentagem } \\
\text { cumulativa }\end{array}$ \\
\hline \multirow[t]{5}{*}{2004} & \multirow[t]{3}{*}{ Válido } & $\begin{array}{c}\text { Não migrou de } \\
\text { Partido } \\
\end{array}$ & 31 & 37,8 & 39,2 & 39,2 \\
\hline & & $\begin{array}{c}\text { Migrou de } \\
\text { Partido }\end{array}$ & 48 & 58,5 & 60,8 & 100,0 \\
\hline & & Total & 79 & 96,3 & 100,0 & \\
\hline & Omisso & Sistema & 3 & 3,7 & & \\
\hline & \multicolumn{2}{|r|}{ Total } & 82 & 100,0 & & \\
\hline \multirow[t]{5}{*}{2008} & \multirow[t]{3}{*}{ Válido } & $\begin{array}{c}\text { Náo migrou de } \\
\text { Partido }\end{array}$ & 51 & 18,4 & 44,3 & 44,3 \\
\hline & & $\begin{array}{c}\text { Migrou de } \\
\text { Partido } \\
\end{array}$ & 64 & 23,1 & 55,7 & 100,0 \\
\hline & & Total & 115 & 41,5 & 100,0 & \\
\hline & Omisso & Sistema & 162 & 58,5 & & \\
\hline & \multicolumn{2}{|r|}{ Total } & 277 & 100,0 & & \\
\hline \multirow[t]{5}{*}{2012} & \multirow[t]{3}{*}{ Válido } & $\begin{array}{c}\text { Não migrou de } \\
\text { Partido }\end{array}$ & 48 & 41,0 & 69,6 & 69,6 \\
\hline & & $\begin{array}{c}\text { Migrou de } \\
\text { Partido }\end{array}$ & 21 & 17,9 & 30,4 & 100,0 \\
\hline & & Total & 69 & 59,0 & 100,0 & \\
\hline & Omisso & Sistema & 48 & 41,0 & & \\
\hline & \multicolumn{2}{|r|}{ Total } & 117 & 100,0 & & \\
\hline \multirow[t]{3}{*}{2016} & Válido & $\begin{array}{c}\text { Não migrou de } \\
\text { Partido } \\
\end{array}$ & 6 & 15,0 & 100,0 & 100,0 \\
\hline & Omisso & Sistema & 34 & 85,0 & & \\
\hline & \multicolumn{2}{|r|}{ Total } & 40 & 100,0 & & \\
\hline
\end{tabular}

Fonte: Elaborado pelas autoras com os dados do TCU e do TSE

Nas eleições de 2004 e 2008, a maior parte dos candidatos havia migrado de partido. Isto se modifica nas eleiçôes de 2012: 41\% dos candidatos com contas irregulares não migraram. Em 2016, sendo o número desses candidatos o mais baixo da série, conseguimos informaçóes para apenas seis deles - 15\% dos candidatos com contas regulares dessa eleição não migraram de partido. Por sua vez, o número de casos ausentes na amostra para essa variável nessa eleição (2016) chegou a impressionantes $85 \%$. Isso pode decorrer simplesmente da metodologia adotada para a construção da variável, que foi: os candidatos foram comparados em duas eleições seguintes e, caso eles não estejam presentes em uma delas, a informação sobre 
migração estará ausente. Observamos que a maioria dos candidatos com contas irregulares de 2016 não disputaram as eleições de 2012, portanto não possuímos informações acerca de sua filiação partidária. A Tabela 5 informa se o candidato com conta irregular era desafiante ou incumbente:

Tabela 5 - Posição do candidato com conta irregular por eleição

\begin{tabular}{|c|c|c|c|c|c|c|}
\hline \multicolumn{3}{|c|}{ Ano da eleiçáo pra prefeito } & \multirow{2}{*}{$\begin{array}{c}\text { Frequência } \\
60\end{array}$} & \multirow{2}{*}{$\begin{array}{c}\text { Porcentagem } \\
73,2\end{array}$} & \multirow{2}{*}{$\begin{array}{c}\text { Porcentagem } \\
\text { válida } \\
75,9\end{array}$} & \multirow{2}{*}{$\begin{array}{l}\text { Porcentagem } \\
\text { cumulativa } \\
75,9\end{array}$} \\
\hline \multirow{5}{*}{$\begin{array}{l}200 \\
4\end{array}$} & \multirow[t]{3}{*}{ Válido } & Desafiante & & & & \\
\hline & & Incumbente & 19 & 23,2 & 24,1 & 100,0 \\
\hline & & Total & 79 & 96,3 & 100,0 & \\
\hline & Omisso & Sistema & 3 & 3,7 & & \\
\hline & \multicolumn{2}{|l|}{ Total } & 82 & 100,0 & & \\
\hline \multirow{5}{*}{$\begin{array}{l}200 \\
8\end{array}$} & \multirow[t]{3}{*}{ Válido } & Desafiante & 167 & 60,3 & 73,6 & 73,6 \\
\hline & & Incumbente & 60 & 21,7 & 26,4 & 100,0 \\
\hline & & Total & 227 & 81,9 & 100,0 & \\
\hline & Omisso & Sistema & 50 & 18,1 & & \\
\hline & \multicolumn{2}{|l|}{ Total } & 277 & 100,0 & & \\
\hline \multirow{3}{*}{$\begin{array}{l}201 \\
2\end{array}$} & \multirow[t]{3}{*}{ Válido } & Desafiante & 82 & 70,1 & 70,1 & 70,1 \\
\hline & & Incumbente & 35 & 29,9 & 29,9 & 100,0 \\
\hline & & Total & 117 & 100,0 & 100,0 & \\
\hline \multirow{3}{*}{$\begin{array}{l}201 \\
6\end{array}$} & \multirow[t]{3}{*}{ Válido } & Desafiante & 36 & 90,0 & 90,0 & 90,0 \\
\hline & & Incumbente & 4 & 10,0 & 10,0 & 100,0 \\
\hline & & Total & 40 & 100,0 & 100,0 & \\
\hline
\end{tabular}

Fonte: Elaborado pelas autoras com base nos dados do TCU e do TSE.

Em todas as eleições ser desafiante foi a categoria de maior representação. No lado oposto, 24,1\% eram incumbentes em 2004, 26,4\% o eram em 2008, 29\% em 2012 e apenas 10\% dos candidatos em 2016. A literatura sobre as vantagens da incumbência é ampla e contundente, e assim ela não deve ser ignorada. Candidatos que possuem mandatos possuem características diferentes dos desafiantes e, por isso, esperamos que o eleitor reaja diferentemente no momento de votar.

Em relação aos resultados eleitorais, temos duas variáveis: votação em primeiro turno e resultado de totalização. Escolhemos avaliar o primeiro turno, dado que é nesse cenário que a primeira opção do eleitor se manifesta.

A Tabela 6 informa a situação eleitoral dos candidatos com contas irregulares. 
I Augusta Teixeira e Marjorie Marona

Tabela 6 - Situação de totalização dos candidatos com contas irregulares por ano eleitoral

\begin{tabular}{|c|c|c|c|c|c|c|}
\hline Ano & \multicolumn{2}{|c|}{$\begin{array}{l}\text { Situação } \\
\text { Eleitoral }\end{array}$} & Frequência & Porcentagem & $\begin{array}{c}\text { Porcentagem } \\
\text { válida }\end{array}$ & $\begin{array}{c}\text { Porcentagem } \\
\text { cumulativa }\end{array}$ \\
\hline \multirow[t]{5}{*}{2004} & \multirow[t]{3}{*}{ Válido } & Não Eleito & 45 & 54,9 & 57,7 & 57,7 \\
\hline & & Eleito & 33 & 40,2 & 42,3 & 100,0 \\
\hline & & Total & 78 & 95,1 & 100,0 & \\
\hline & Omisso & Sistema & 4 & 4,9 & & \\
\hline & \multicolumn{2}{|c|}{ Total } & 82 & 100,0 & & \\
\hline \multirow[t]{5}{*}{2008} & \multirow[t]{3}{*}{ Válido } & Não Eleito & 147 & 53,1 & 64,8 & 64,8 \\
\hline & & Eleito & 80 & 28,9 & 35,2 & 100,0 \\
\hline & & Total & 227 & 81,9 & 100,0 & \\
\hline & Omisso & Sistema & 50 & 18,1 & & \\
\hline & \multicolumn{2}{|c|}{ Total } & 277 & 100,0 & & \\
\hline \multirow[t]{3}{*}{2012} & \multirow[t]{3}{*}{ Válido } & Não Eleito & 81 & 69,2 & 69,2 & 69,2 \\
\hline & & Eleito & 36 & 30,8 & 30,8 & 100,0 \\
\hline & & Total & 117 & 100,0 & 100,0 & \\
\hline \multirow[t]{3}{*}{2016} & \multirow[t]{3}{*}{ Válido } & Não Eleito & 27 & 67,5 & 67,5 & 67,5 \\
\hline & & Eleito & 13 & 32,5 & 32,5 & 100,0 \\
\hline & & Total & 40 & 100,0 & 100,0 & \\
\hline
\end{tabular}

Fonte: Elaborado pelas autoras com os dados do TCU e do TSE.

Segundo os dados acima, $57,7 \%$ dos candidatos com contas irregulares em 2004 não tiveram sucesso nas eleições. Esse número subiu nas eleições de 2008, alcançando 64,8\%. Em 2012, cerca de 69\% dos candidatos com contas irregulares não foram eleitos. Este número teve uma pequena queda na eleição de 2016, indo para $67,5 \%$.

Percebemos que estar vinculado a problemas de contas julgadas como irregulares tem efeito negativo na chance de sucesso eleitoral. Cabe uma nota acerca dos casos ausentes: muitos destes são de responsabilidade da atuação da justiça. Em conjunto, essas instituições acabam por indeferir a candidatura ou o resultado eleitoral daqueles com problemas na justiça. Em decorrência dessa atuação, os órgãos partidários também substituíram alguns de seus candidatos, o que mostra um indício do papel que as instituições judiciais têm no que tange a legislação eleitoral.

Observamos que as diferenças em termos de votação, em primeiro turno, foram encontradas somente nas duas últimas eleiçóes, podendo estar relacionadas à atuação da justiça e ao combate à corrupção após a promulgação da "Lei Ficha Limpa". Esses candidatos com altas votaçôes em primeiro turno poderiam ser

${ }^{5}$ Lei Complementar no 135 , de 4 de junho de 2010. 
derrotados em segundo turno, por isso é imprescindível que se avalie o resultado da eleição. Nossa análise descritiva indica que, em sua maioria, candidatos envolvidos em contas irregulares não são eleitos para todas as eleições na amostra. Avaliaremos agora se esses dados se confirmam quando avaliados em um teste estatístico.

Dado que objetivamos testar a hipótese de que estar envolvido com processos de contas irregulares exerce um efeito negativo sobre a probabilidade de ser eleito, usaremos um modelo de regressão logística binária.

Em primeiro lugar, avaliemos a distribuição de nossa variável independente dados os valores de nossa variável dependente:

Tabela 7 - Eleitos

\begin{tabular}{c|c|c|c|c}
\hline & & \multicolumn{2}{|c|}{ Eleito? } & \multirow{2}{*}{ Total } \\
\hline & & Não & Sim & \\
\hline \multirow{2}{*}{ Conta Irregular } & Não & 63,39 & 35,85 & 99,24 \\
\cline { 2 - 5 } & Sim & 0,49 & 0,27 & 0,76 \\
\hline Total & & 63,88 & 36,12 & 100 \\
\hline
\end{tabular}

Fonte: Elaborado pelas autoras com os dados do TCU e do TSE.

Abaixo apresentamos o cruzamento entre ter conta irregular e ser ou não eleito. Em toda a amostra, candidatos com contas irregulares representam 0,76. Destes 0,49 estão entre os não eleitos e 0,27 entre os eleitos. A tabela abaixo apresenta a contingência da variável independente com a variável dependente:

Tabela 8 - Conta irregular por situação eleitoral

\begin{tabular}{c|c|c|c|c}
\hline & & \multicolumn{2}{|c|}{ Eleito? } & Total \\
\hline & & Não & Sim & \\
\hline \multirow{2}{*}{ Conta Irregular } & Não & 63,88 & 36,12 & 100 \\
\cline { 2 - 5 } & Sim & 64,94 & 35,06 & 100 \\
\hline
\end{tabular}

Fonte: Elaborado pelas autoras com os dados do TCU e do TSE.

No geral, apenas 35\% dos envolvidos com contas irregulares foram eleitos. Isso segue o padrão da distribuição geral entre eleitos e não eleitos. Então, estimaremos um modelo de regressão logística, seguindo a família dos modelos de ligação binomial logit. Nossa principal variável independente é se o candidato teve sua conta considerada irregular no ciclo eleitoral que ele disputou, e está codificada como 0 para "não" e 1 para "sim". Além disso, podemos esperar que, se o candidato é 
incumbente ou não pode estar relacionado tanto com nossa variável dependente (vantagem do incumbente) quanto com a nossa variável independente, isso afeta a probabilidade do eleitor punir esse tipo de candidato. Avaliamos também o efeito do candidato ser migrante ou não.

Inserimos algumas variáveis de controle, como o gasto de campanha dos candidatos, dado seus efeitos, já apontados pela literatura, sobre a chance de sucesso eleitoral. Adicionamos também o PIB per capita dos municípios para controlarmos os fatores de desenvolvimento social e econômico de cada um deles. Inserimos variáveis dummy para controlar o ano da eleição e as possíveis contextualidades de cada pleito no período. O ano de 2004 é o ano de referência. O teste de Wald para a significância desses coeficientes atesta para a necessidade de manutenção das variáveis.

A Tabela 9 sumariza seis modelos: a estratégia seguida para a elaboração foi a inserção de uma variável por vez para observar as mudanças nos coeficientes, dado o padrão de interação entre as variáveis. $\mathrm{O}$ objetivo é identificar se os candidatos com contas irregulares foram punidos eleitoralmente. Esperamos que o efeito (B) de ter conta irregular seja negativo e significativo.

O modelo 1 possui a nossa variável independente e das demais variáveis de controle (com exceção de gasto de campanha). O efeito de ter conta irregular sobre a probabilidade de ser eleito é -0,082 ( $\log$-odds), indicando que a chance de ser eleito diminui quando o candidato teve uma conta rejeitada no ciclo eleitoral em que ele disputou as eleições, mantendo o PIB per capita e o ano eleitoral constante ${ }^{6}$. Em termos de razão de chance (odds ratio), um candidato com as contas rejeitadas possui uma razão de chance de ser eleito reduzida em 0,920 quando comparado com aqueles candidatos que não possuem essa característica. Isso é uma redução de $-7,96 \%$ na chance de ser eleito ${ }^{7}$ em relação aos candidatos "limpos". Contudo, esse coeficiente não foi significativo. Além disso, esse modelo ainda não leva em conta variáveis explicativas do sucesso eleitoral.

\footnotetext{
${ }^{6}$ Tanto o PIB per capta quanto os anos eleitorais foram significantes para a maior parte dos modelos. Contudo, sendo apenas variáveis de controle, não daremos atenção especial a elas no corpo do texto. ${ }^{7}$ Tendo a seguinte fórmula: chance(eleito|irregular $)=(\exp (\text { coeficiente })-1)^{*} 100$. Isso nos dá a chance percentual de ocorrência do evento.
} 
Tabela 9 - Modelo de Regressão Logística. Variável dependente: Eleito ou Não Eleito

\begin{tabular}{|c|c|c|c|c|c|c|}
\hline & (1) & (2) & (3) & (4) & (5) & (6) \\
\hline \multicolumn{7}{|l|}{$\begin{array}{c}\text { Variáveis } \\
\text { independentes }\end{array}$} \\
\hline \multirow[t]{3}{*}{ Conta irregular } & -0.083 & -0.028 & -0.107 & $-0.404^{* *}$ & $-0.708^{* * *}$ & $-0.694^{* * *}$ \\
\hline & $(0.099)$ & $(0.104)$ & $(0.107)$ & $(0.137)$ & $(0.198)$ & $(0.196)$ \\
\hline & {$[0.920]$} & {$[0.972]$} & [0.899] & {$[0.668]$} & {$[0.493]$} & [0.499] \\
\hline \multirow[t]{3}{*}{ Incumbente } & & & 1.054 *** & $0.625^{* * *}$ & $0.618^{* * *}$ & $0.624^{* * *}$ \\
\hline & & & $(0.024)$ & $(0.030)$ & $(0.030)$ & $(0.030)$ \\
\hline & & & [2.869] & [1.868] & {$[1.856]$} & {$[1.867]$} \\
\hline \multirow[t]{3}{*}{ Migração } & & & & $-0.203^{* * *}$ & $-0.205^{* * *}$ & $-0.210^{* * *}$ \\
\hline & & & & $(0.030)$ & $(0.030)$ & $(0.030)$ \\
\hline & & & & {$[0.816]$} & {$[0.815]$} & {$[0.811]$} \\
\hline \multirow[t]{3}{*}{$\begin{array}{c}\text { Conta Irregular x } \\
\text { Incumbente }\end{array}$} & & & & & $0.639^{* * *}$ & \\
\hline & & & & & $(0.284)$ & \\
\hline & & & & & [1.894] & \\
\hline \multirow[t]{3}{*}{$\begin{array}{c}\text { Conta Irregular x } \\
\text { Migração }\end{array}$} & & & & & & 0.580 * \\
\hline & & & & & & $(0.274)$ \\
\hline & & & & & & {$[1.785]$} \\
\hline \multicolumn{7}{|l|}{ Controles $^{8}$} \\
\hline \multirow[t]{3}{*}{$\begin{array}{c}\text { Gasto de } \\
\text { Campanha }\end{array}$} & & $0.000^{* * *}$ & $0.000^{* * *}$ & $0.000^{* * *}$ & $0.000^{* * *}$ & $0.000^{* * *}$ \\
\hline & & $(0.000)$ & $(0.000)$ & $(0.000)$ & $(0.000)$ & $(0.000)$ \\
\hline & & {$[1.000]$} & {$[1.000]$} & {$[1.000]$} & {$[1.000]$} & {$[1.000]$} \\
\hline \multirow[t]{3}{*}{ PIB Per capta } & $-0.000^{* * *}$ & $-0.000^{* * *}$ & $-0.000^{* * *}$ & $-0.000 *$ & $-0.000 *$ & $-0.000^{*}$ \\
\hline & $(0.000)$ & $(0.000)$ & $(0.000)$ & $(0.000)$ & $(0.000)$ & $(0.000)$ \\
\hline & {$[1.000]$} & {$[1.000]$} & {$[1.000]$} & {$[1.000]$} & {$[1.000]$} & {$[1.000]$} \\
\hline \multirow[t]{3}{*}{ Eleição 2008} & $0.107^{* * *}$ & -0.003 & $-0.070^{* *}$ & $0.348^{* * *}$ & $0.348^{* * *}$ & $0.345^{* * *}$ \\
\hline & $(0.024)$ & $(0.026)$ & $(0.027)$ & $(0.038)$ & $(0.038)$ & $(0.038)$ \\
\hline & {$[1.112]$} & {$[0.997]$} & [0.933] & {$[1.416]$} & {$[1.417]$} & {$[1.412]$} \\
\hline Eleição 2012 & $0.072^{* *}$ & -0.038 & -0.047 & $0.224^{* * *}$ & $0.225^{* * *}$ & $0.223^{* * *}$ \\
\hline
\end{tabular}

8 Infelizmente foi necessário retirar a variável de tamanho populacional já que ela apresentava problemas para a estimação do modelo. 
I Augusta Teixeira e Marjorie Marona

\begin{tabular}{c|l|l|l|l|l|l}
\hline & $(0.024)$ & $(0.026)$ & $(0.027)$ & $(0.041)$ & $(0.041)$ & $(0.041)$ \\
\hline & {$[1.074]$} & {$[0.963]$} & {$[0.954]$} & {$[1.252]$} & {$[1.252]$} & {$[1.250]$} \\
\hline Eleição 2016 & -0.020 & $-0.1011^{* * *}$ & $-0.123^{* * *}$ & $0.085^{*}$ & $0.086^{*}$ & $0.083^{*}$ \\
\hline & $(0.025)$ & $(0.027)$ & $(0.027)$ & $(0.039)$ & $(0.039)$ & $(0.039)$ \\
\hline & {$[0.980]$} & {$[0.904]$} & {$[0.884]$} & {$[1.089]$} & 1.090 & {$[1.087]$} \\
\hline Constante & $-0.565^{* * *}$ & -0.384 & $-0.551^{* * *}$ & $-0.343^{* * *}$ & $-0.341^{* * *}$ & $-0.338^{* * *}$ \\
\hline & $(0.018)$ & 0.020 & $(0.020)$ & $(0.033)$ & $(0.033)$ & $(0.033)$ \\
\hline & {$[0.568]$} & 0.681 & {$[0.576]$} & {$[0.709]$} & {$[0.711]$} & {$[0.713]$} \\
\hline Medidas de Ajuste & & & & & & \\
\hline Log Likelihood & - & - & - & - & - & - \\
& 39494.244 & 35280.835 & 34264.312 & 17081.903 & 17079.301 & 17079.650 \\
\hline AIC & 79000 & 70576 & 68545 & 34182 & 34179 & 34179 \\
\hline BIC & 79054.540 & 70637.810 & 68615.64 & 34255.140 & 34260.080 & 34260.780 \\
\hline $\mathrm{R}^{2}$ McFadden & 0.013 & 0.118 & 0.143 & 0.573 & 0.573 & 0.573 \\
\hline $\mathrm{N}$ & 60437 & 52968 & 52968 & 25547 & 25547 & 25547 \\
\hline Nota: Coficientes
\end{tabular}

Nota: Coeficientes em log-odds. Erro padrão entre parênteses. Odds ratio entre colchetes. Asteriscos nos coeficientes indicam a significância do teste estatístico: ${ }^{* * *} \mathrm{p}<0.001 ;{ }^{* *} \mathrm{p}<0.01 ;{ }^{*} \mathrm{p}<0.05$. Fonte: Elaborado pelas autoras com os dados do TCU e do TSE.

No modelo 2, inserimos o gasto de campanha para observar as mudanças no coeficiente de conta irregular e no ajuste do modelo. $O$ gasto de campanha é estatisticamente significativo $(\mathrm{p}<0,001)$ e melhorou o ajuste do modelo $\left(\mathrm{R}^{2}\right.$ Mcfadden $=0,118)^{9}$. Nossa variável independente de interesse continua com o sinal negativo, mas não apresenta significância em termos estatísticos. A razão de chance de ser eleito é 0,972 quando o candidato possui conta irregular em relação àqueles que não possuem. Nesse caso, ela ainda sofreu pequeno aumento em relação ao modelo anterior, indicando que, quando controlado pelo gasto de campanha, a probabilidade de eleito aumenta, embora continue muito baixo. Um candidato com conta irregular tem sua chance de ser eleito reduzida em $-2,76 \%$. Salientamos que esse coeficiente não foi significativo.

O modelo 3 apresenta a mesma relação, agora com a inserção da variável incumbente, codificada com 1 se o candidato é mandatário e 0 se não é. Como

\footnotetext{
${ }^{9}$ Utilizamos o Pseudo $\mathrm{R}^{2}$ de McFadden como medida de ajuste por ele ser mais conservador do que os alternativos Cox e Snell e Cragg and Uhler. De qualquer modo, reportamos outras medidas de ajuste, dado as limitaçóes que os cálculos de $\mathrm{R}^{2}$ em modelos não lineares possuem.
} 
sabemos, essa variável é essencial para os estudos de competição eleitoral. De acordo com o modelo, essa variável é significativa estatisticamente ao nível de $\mathrm{p}<0,001$ e apresenta um coeficiente de $1.054 \mathrm{em} \log$-odds. Isso indica que a razão de chance de um candidato incumbente ser eleito (reeleito, no caso) é de 2,869 vezes maior do que o candidato desafiante. Novamente, a variável conta irregular continua apresentando um efeito negativo, contudo sem significância estatística. De qualquer modo, controlando pelo gasto de campanha e pela situação do candidato (incumbente ou desafiante), o modelo fortalece a ideia de que candidatos com conta irregular têm uma probabilidade menor de vitória. A chance desse candidato ser eleito é -10,15\% em relação aos candidatos normais. Esse modelo 3 também apresentou sinais de melhora em relação ao anterior. Os modelos 4 e 6 são aqueles que melhor se ajustam e são os mais significativos em relação ao nosso objeto. Nos últimos modelos, nossa variável independente, apresentou coeficiente negativo e significativo.

Inserimos os dados de migraçáo partidária no modelo 4. Essa variável se mostrou estatisticamente significativa $(\mathrm{p}<0,001)$ e com efeito negativo sobre $o$ sucesso eleitoral. Segundo as estimativas, a log-odds de ser eleito diminui em -0,203 quando se migra de partido, dando uma razão de chance de 0,816 menor de ser eleito quando comparado com não migrantes. Ser incumbente segue sendo positivo e significativo sobre o sucesso eleitoral ( $\log$-odds 0,$625 ; \mathrm{p}<0,001)$. A mudança ocorreu na nossa variável independente de interesse. Possuir conta irregular passou a ser significativo neste modelo. Segundo a tabela, o efeito de ter uma conta irregular sobre a probabilidade de sucesso eleitoral é de -0,404 log-odds. Isso dá uma razão de chance de 0,668 menor do que aqueles candidatos que concorreram sem esses problemas. Esse coeficiente passou a ser significativo a $\mathrm{p}<0,01$. Conforme esse modelo, os candidatos com contas irregulares, possuem uma redução de $-33,24 \%$ na chance de serem eleitos, mantendo constantes os status de incumbência, de migraçáo partidária e gastos de campanha. O modelo também passou a ser bem melhor especificado. Todas as medidas desse tipo apresentaram uma melhora considerável comparada aos modelos anteriores.

Os modelos 3 e 4 indicaram que existe uma relação entre concorrer com irregularidades nas contas com o fato de o candidato ser incumbente ou não e se o candidato migrou ou não de partido, dadas as mudanças tanto nos coeficientes quanto na significância estatística deles. Os próximos modelos tentam lidar com essa nova informação inserindo termos interativos nas relações. Contudo, é nítido que a redução do número de casos com informação disponível para essas variáveis é bem 
menor. Por isso, não poderemos explorar o máximo de possibilidades de interação entre as variáveis.

No modelo 5, inserimos uma interação entre concorrer com contas irregulares e se o candidato é incumbente ou não. $\mathrm{O}$ coeficiente para incumbente continuou significativo e sofreu uma leve redução quando comparado com o modelo 4. A interação que inserimos entre concorreu com conta irregular e se o candidato era incumbente possui um efeito positivo e significativo sobre a chance de ser eleito. $\mathrm{O}$ $\log$-odds é 0,639, com uma razão de chance de 1,894 vezes mais de ser eleito em relação aos não incumbentes e não irregulares. Essa interação demonstra que o efeito negativo de ter conta irregular não afeta a chance de sucesso dos incumbentes. Pressupomos que esses candidatos fazem uso da máquina política para se livrar dos aspectos negativos associados aos problemas com a justiça. Entretanto, ainda podemos extrair mais informaçóes do nosso modelo 5. Nossa variável recebeu um incremento no seu poder explicativo ao inserirmos a interação. Ou seja, considerando um indivíduo não incumbente, concorrer às eleições tendo contas tidas como irregulares pelo TCU tem um efeito de $-0.708 \log$-odds na chance de ser eleito. Em termos de razão de chance, o modelo estima uma razão de chance 0,493 vezes menor de ser eleito, nos dando uma razáo de chance percentual $-50,74 \%$ de ser eleito quando o candidato tem a conta irregular, mantendo-se os demais fatores constantes.

Por fim, o modelo 6 apresenta as informaçóes para a interação entre concorrer com contas irregulares e migração partidária. $O$ modelo não apresenta ganhos estatísticos importantes em relação ao anterior. Mostra, contudo, que a interação entre conta irregular e migração de partido é positiva e significativa. Migrar de partido tendo uma conta irregular dá uma chance de vitória de 0,580 log-odd e uma razão de chance de 1,785 vezes mais de ser eleito em relação aos candidatos sem conta irregular e que não migraram de partido. Esse dado é bastante interessante porque, uma vez que tanto o efeito de migrar de partido quanto o efeito de concorrer com conta irregular são negativos, o candidato com conta irregular consegue sobrepor esses efeitos negativos ao migrar de partido. Essa interação não retirou o efeito negativo e significativo de concorrer com conta irregular sobre a chance de ser eleito. Em termos de razão de chance, candidatos com conta irregular observam uma diminuição de 0,499 vezes mais em relação aos candidatos sem essa característica. Isso significa $-50,04 \%$ de chance de ser eleito.

De maneira geral, possuir conta irregular tem efeito negativo sobre a chance de ser eleito. Contudo, esse efeito só é significativo quando controlado por características do candidato, tais como receita de campanha, se é incumbente e 
migração partidária. Nossos resultados indicam que, mantendo essas características constantes, concorrer com contas irregulares diminui as chances de sucesso eleitoral. Adicionalmente, identificamos que os candidatos incumbentes passam imunes a esse efeito. Uma questão que fica para ser explicada é o efeito de migração partidária, já que os candidatos com contas irregulares que migram de partido tem êxito eleitoral. Isso pode se dar em função do número reduzido de casos e ou sua relação com a própria incumbência.

Portanto, podemos observar que os eleitores podem estar se utilizando de informaçóes e, assim, sendo capazes de utilizar de seu dispositivo de sanção (accountability vertical) ao punir sujeitos com problemas judiciais, no caso, com contas julgadas como irregulares pelo TCU. Os dados que utilizamos são uma evidência parcial de que os eleitores têm punido esse tipo de candidato.

\section{Considerações finais}

A accountability deve funcionar por meio de diversos mecanismos e instituições de controle (MAINWARING, 2003). Neste artigo, tratamos da interação entre accountability vertical (eleições) e uma outra instituição de controle, no caso o Tribunal de Contas da União (TCU), que atua realizando a accountability horizontal.

Entendemos que indivíduos geralmente votam em situações em que as informações sobre suas escolhas não chegaram a ele perfeitamente (MORTON e TYRAN, 2015). Além disso, as informaçôes são distribuídas de modo assimétrico, em que alguns eleitores tem mais conhecimento que outros (MORTON e TYRAN, 2015). Sem essas informaçóes, torna-se difícil para o eleitor utilizar seu voto como estratégia de punir candidatos corruptos, ou seja, o dispositivo de accountability vertical se torna uma ferramenta ineficaz.

Propomos neste trabalho responder se candidatos a prefeito com problemas em suas contas são punidos eleitoralmente. Segundo Pereira e Melo (2015), nas eleições municipais de 2008, os prefeitos candidatos que concorreram à reeleição em 20 dos 27 municípios da capital do estado foram reeleitos. Destes, dezenove haviam sido investigados por algum crime relacionado à corrupção (PEREIRA e MELO, 2015). Assim, tentamos investigar um pouco mais sobre esse cenário das eleições municipais. Nossa hipótese é que, se um indivíduo possui contas irregulares com o Tribunal de Contas da União, então haverá um efeito negativo na probabilidade de ele se eleger. 
Coletamos os dados do TCU referentes às contas irregulares, os dados de disputas eleitorais para prefeitura disponíveis no Tribunal Superior Eleitoral e dados do Instituto Brasileiro de Estatística e Geografia sobre os municípios.

Cabe ao TCU sinalizar sobre as contas irregulares de indivíduos públicos ou não que prestaram serviços para o setor público. Entretanto, cabe à Justiça Eleitoral decidir aplicar uma penalidade.

A variável independente do estudo é o resultado eleitoral, sendo eleito ou não eleito. Coletamos também gasto de campanha, se o indivíduo é incumbente ou não e se há migração partidária em comparação com a eleição anterior, utilizadas como variáveis de controle. Também utilizamos como variável de controle a unidade geográfica: população do município e renda per capita. Queremos impedir que a relação entre pobreza e corrupção interfira nos nossos testes de hipótese.

Utilizamos um modelo de regressáo logística para estimar o efeito de uma ou mais variáveis independentes em uma determinada variável dependente binária - no caso, se o candidato foi eleito ou não.

Observamos que a média do número de processos dos candidatos com contas irregulares por ciclo eleitoral é de 1,37 e que, dos 516 candidatos que concorreram às eleiçôes tendo um processo de contas irregulares, $78,9 \%$ respondiam a apenas um processo. O tempo de julgamento dos processos dos candidatos também foi observado, alcançando uma média de 3,93 anos para um processo ser julgado.

Ressaltamos o período entre os anos 2004 a 2016. Em 2008, 277 candidatos com contas irregulares disputaram as eleiçôes, sendo o ano com maior número de candidatos desse tipo.

Os partidos que mais apresentaram candidatos com contas irregulares na nossa amostra foram: PMDB (21,12\%), PSDB (13,18\%) e PR $(8,72 \%)$.

Em todas as eleições observadas, havia mais desafiantes do que incumbentes com o perfil que trabalhamos.

Nossos resultados apresentam que é mais difícil para um candidato vencer as eleições tendo contas irregulares pelo TCU.

Inserimos uma variável por vez visando observar as mudanças nos coeficientes conforme a interação entre essas variáveis, totalizando seis modelos.

No primeiro modelo o efeito de ter conta irregular sobre a probabilidade de ser eleito é - $0,082(\log$-odds), indicando que a chance de ser eleito diminui quando o candidato teve uma conta rejeitada no ciclo eleitoral em que ele disputou as eleiçóes, mantendo o PIB per capita e o ano eleitoral constante. 
No segundo modelo inserimos a variável de gasto de campanha para observar as mudanças no coeficiente de conta irregular e no ajuste do modelo. A variável sofreu um leve aumento em relação ao modelo anterior, indicando que, quando controlada pelo gasto de campanha, a probabilidade de eleito aumenta, embora continue muito baixa.

No terceiro modelo, a variável incumbente foi inserida. Observamos que as chances de um candidato incumbente ser reeleito são 2,869 vezes maiores do que o candidato desafiante. Mas o modelo ainda fortalece a ideia de que candidatos com conta irregular tem uma probabilidade menor de ser eleito.

$\mathrm{O}$ quarto modelo teve a variável de migração partidária inserida e estatisticamente significativa, com efeito negativo sobre o sucesso eleitoral. As chances de um candidato ser eleito ao migrar de partido são reduzidas, dando uma razão de chance 0,816 menor de ser eleito em comparação com não migrantes. Ser incumbente continuou a ser positivo e significativo sobre o sucesso eleitoral.

No quinto modelo inserimos uma interação entre concorrer com contas irregulares e ser incumbente ou não. Essa interação possui um efeito positivo e significativo sobre a chance de ser eleito. Ou seja, observamos que ter conta irregular não afeta o sucesso eleitoral dos incumbentes.

O último modelo apresenta as informações para a interação entre concorrer com contas irregulares e migração partidária. Observamos que a interação entre conta irregular e migração de partido é positiva e significativa, ou seja, migrar de partido quando se tem contas irregulares aumenta as chances de sucesso eleitoral. Essa interação, contudo, não retirou o efeito negativo e significativo de se concorrer com conta irregular sobre a chance de ser eleito.

Possuir contas irregulares dificulta o sucesso eleitoral. Entretanto, esse efeito só é significativo quando controlado por características do candidato, tais como receita de campanha, ser incumbente e migração partidária. Porém, candidatos incumbentes conseguem passar imunes a esse efeito.

Como qualquer trabalho, este tem suas limitações: não trabalhamos com a variável de mídia, que influencia bastante o eleitorado, não mensuramos a competição eleitoral, e também não foi mensurado o apoio dos governadores. Ainda, não medimos o efeito da lei da Ficha Limpa. Também devemos salientar que o recorte da nossa amostra é considerado pequeno comparado ao tamanho do banco de dados do TCU. 
A literatura indica a dificuldade do eleitor em punir candidatos em cenários reais de contravençóes (BOAS, HIDALGO e MELO, 2019), e este trabalho segue a mesma linha ao observar essa dificuldade. O que podemos ver é que o eleitor consegue punir indivíduos que não têm histórico político; neste caso, entendemos histórico político como sujeitos que não pleitearam eleiçóes previamente. Porém, a capacidade do eleitor de punir se restringiu apenas a isso. Portanto, quando alguém com histórico político, ou seja, sujeitos que já tiveram cargos competitivos na política, buscam por reeleição, o eleitor tem dificuldades severas em penalizá-los. Infelizmente, neste caso, a accountability vertical se torna um instrumento débil para punir candidatos com o perfil que estudamos.

Augusta Teixeira é Doutoranda em Ciência Política pela Universidade Federal de Minas Gerais. E-mail: augustateixeira31@gmail.com.

Marjorie Marona é Professora Doutora do Departamento de Ciência Política da Universidade Federal de Minas Gerais. E-mail: maronamarjorie@gmail.com.

\section{Referências}

ARANTES, Rogério; COUTO, Cláudio. Construção Democrática e Modelos de Constituição. Dados - Revista de Ciências Sociais, v. 53, n. 3, p. 545-585, 2010.

BOAS, Taylor C.; HIDALGO, F. Daniel; MELO, Marcus A. Norms versus Action: Why Voters Fail to Sanction Malfeasance in Brazil. American Journal of Political Science, v. 63, n. 2, p. 385-400, 2019.

BORGES, André. Já não se fazem mais máquinas políticas como antigamente. Revista de Sociologia e Política, v. 18, n. 35, p. 167-188, 2010.

DAHL, Robert. A. Poliarquia: participação e oposição. São Paulo: Edusp, 2012. Sobre a democracia. Brasília: Editora Universidade de Brasília, 2001.

DEININGER, Klaus; SQUIRE, Lyn. A new data set measuring income inequality. The World Bank Economic Review, v. 10, n. 3, p. 565-591, 1996.

FEARON, James D. Electoral Accountability and the control of politicians: selecting good types versus sanctioning poor performance. In: PRZEWORSKI, Adam.; STOKES, Susan; MANIN, Bernard. Democracy, accountability and representation. Cambrigde: Cambridge University Press, 1999. p. 55-97. 
FILGUEIRAS, Fernando; MARONA, Marjorie C. A corrupção, o Judiciário e a cultura política no Brasil democrático. In: BIASON, Rita (Org.). Temas de corrupção política. São Paulo: Balão Editoral, 2012. p. 99-136.

GELMAN, Andrew; KING, Gary. Estimating incumbency advantage without bias. American Journal of Political Science, v. 34, p. 1142-1164, 1990.

JACOBSON, Gary C. Money and votes reconsidered: Congressional elections, 1972-1982. Public Choice, v. 47, n. 1, p. 7-62, 1985.

MAINWARING, Scott. Introduction: democratic accountability in Latin America. In: MAINWARING, Scott; WELNA, Christopher (Eds.). Democratic accountability in Latin America. New York: Oxford University Press, 2003. p. 3-33.

MANIN, Bernard; PRZEWORSKI, Adam; STOKES, Susan. Elections and representation. In: PRZEWORSKI, Adam; STOKES, Susan; MANIN, Bernard. Democracy, accountability and representation. Cambrigde: Cambridge University Press, 1999. p. 29-54.

MEIRELES, Fernando; SILVA, Denisson; COSTA, Beatriz. electionsBR: R functions to download and clean Brazilian electoral data. Belo Horizonte: Federal University of Minas Gerais (UFMG), 2016.

MELO, Carlos Ranulfo. Migração partidária, estratégias de sobrevivência e governismo na câmara dos deputados. XXVI Encontro Nacional da ANPOCS, 2002, Caxambú - MG. Disponível em: <https://anpocs.com/index.php/papers-26-encontro/gt-23/gt08-19/4394-crmelo-migracao/file>.

Acesso em: 09 maio 2019.

MORTON, Rebecca; TYRAN, Jean-Robert. Corruption in committees: an experimental study of information aggregation through voting. Journal of Public Economic Theory, v. 17, n. 4, p. 553$579,2015$.

O'DONNELL, Guillermo. Accountability horizontal e novas poliarquias. Lua Nova: Revista de Cultura e Política, n. 44, p. 27-54, 1998.

PEREIRA, Carlos; MELO, Marcus. Reelecting corrupt incumbents in exchange for public goods: Rouba mas faz in Brazil. Latin American Research Review, v. 50, n. 4, p. 88-115, 2015.

PEREIRA, Carlos; RENNÓ, Lucio; SAMUELS, David. Corruption, campaign finance, and reelection. In: POWER, Timothy J.; TAYLOR, Matthew M. Corruption and democracy in Brazil: The struggle for accountability. Notre Dame: University of Notre Dame Press, 2011.

R CORE TEAM. R: A language and environment for statistical computing. Vienna, Austria: R Foundation for Statistical Computing, 2016. Disponível em: <https://www.R-project.org/>. Acesso em: 09 maio 2019.

TOMIO, Fabricio; ROBL FILHO, Ilton. Accountability e independência judiciais: uma análise da competência do Conselho Nacional de Justiça (CNJ). Revista de Sociologia e Política, Paraná, v. 21, n. 45, p. 29-46, 2013.

WINTERS, Matthew; WEITZ-SHAPIRO, Rebecca. Lacking information or condoning corruption: when do voters support corrupt politicians? Comparative Politics, v. 45, n. 4, p. 418-436, 2013.

Texto recebido em 15 de dezembro de 2018. Aprovado em 12 de junho de 2019. 